\title{
IMAGEM CORPORAL: A percepção do conceito em indivíduos obesos do sexo feminino
}

\author{
Corporal image: The perception of the concept in obese female
}

\author{
Guidélia Aparecida da Silva ${ }^{[a]}$ Elaine Soares Neves Lange ${ }^{[b]}$ \\ ${ }^{[a]}$ Aluna do Curso de Psicologia da Universidade São Francisco, Jardim América, SP - Brasil, e-mail: guiapesil@hotmail.com \\ ${ }^{[b]}$ Psicóloga, professora, Doutora em Psicologia Clínica pela Universidade de São Paulo (USP), Ribeirão Pires, SP - Brasil, e-mail: \\ ellange@usp.br
}

\section{Resumo}

O presente trabalho apresenta o conceito de imagem corporal e suas correlações com a obesidade feminina. O objetivo deste foi identificar, analisar e correlacionar os aspectos psicológicos sobre a imagem corporal em indivíduos obesos do sexo feminino, utilizando como método a pesquisa bibliográfica. Os resultados da pesquisa apontam que a obesidade em indivíduos obesos do sexo feminino desencadeia aspectos psicológicos, tais como: baixa auto-estima, ansiedade, angústia, agressividade, tristeza, compulsão, negação, insatisfação com a imagem corporal. O indivíduo obeso do sexo feminino também projeta sua culpa num objeto ou pessoa, levando-se em conta que o fator sociocultural tem grande importância sobre os aspectos psicológicos. Concluiu-se que, os indivíduos obesos do sexo feminino desencadeiam dificuldades nesses aspectos, devido a um fragilizado vínculo mãe-filho, acrescentando-se a importância sobre a etiologia multifatorial da obesidade, em que a cultura apresenta-se como um fator relevante.

Palavras-chave: Obesidade. Gênero feminino. Imagem corporal. Cultura.

\begin{abstract}
The current paper presents the concept of body image and its relations to the feminine obesity. The objective of this paper was to identify, analyze and correlate the psychological aspects on corporal image in obese female individuals, using the bibliographical research as a method. The research results show that obesity in female individuals present psychological aspects, such as: low self-esteem, anxiety, anguish, anger, sadness, compulsion, denial, and
\end{abstract}


dissatisfaction concerning the corporal image. The obese female individuals also project their guilt onto an object or person, taking into account that the socio-cultural factor has great importance on the psychological aspects. It was concluded that obese female individuals present difficulties in these aspects, due to a fragile mother-child bond, adding the importance on the multifactor etiology of obesity, making culture a relevant factor.

Keywords: Obesity. Female gender. Corporal image. Culture.

\section{INTRODUÇÃO}

Esta pesquisa aborda um problema de saúde pública que atinge não só os brasileiros, mas grande parte da população mundial: a obesidade.

Objetivou-se levantar e analisar aspectos psicológicos relacionados à imagem corporal em indivíduos obesos do sexo feminino, visando a identificar os aspectos relevantes, pois o cuidado que as mulheres têm com a própria aparência física apresenta-se como um fator que pode lhes conferir críticas ou admiração na sociedade em que vivem.

Nunes (1998) define a obesidade como uma doença epidêmica, que tem acometido até indivíduos de países orientais, onde essa tendência mostrava-se pouco expressiva. O crescimento da obesidade no mundo moderno deve-se à interação entre fatores genéticos e ambientais.

Atualmente, muitos indivíduos, principalmente as mulheres, vivem em busca de um "padrão de beleza" pelo qual se sacrificam constantemente, a fim de manterem seus corpos magros, esbeltos, num ritmo frenético, obedecendo e escravizando-se por imposições estéticas e sociais. Esses padrões modificam-se cotidianamente, e a cada dia torna-se mais difícil enquadrarse nesse modelo (Couto, 2004).

Schilder (1999) defende que a imagem corporal sofre influências da imagem visual, tátil e postural, porque ao entrarmos em contato com o mundo através desses sentidos, a textura, as formas humanas ou de objetos fazem com que assumamos uma nova representação mental sobre determinado aspecto. O autor salienta que o corpo está em constante mudança, influenciado pelos ciclos da vida, em que cada pessoa deverá vivenciar essas alterações, adaptando-se com aceitação. Caso isso não ocorra, o indivíduo sofrerá, por conceber uma imagem corporal real que contraria a "ideal", no que se refere ao seu mundo interno e externo, quando esse foge aos padrões impostos pela sociedade.

A escolha do tema foi baseada em observações que detectaram a presença de aspectos psicológicos, como a ansiedade, a agressividade, a tristeza e, em alguns casos, um índice de insatisfação pessoal elevado - observados no contato com indivíduos obesos do sexo feminino.

O problema de pesquisa foi elaborado através da hipótese de que os indivíduos obesos do sexo feminino subestimam sua capacidade intelectual e interpessoal, por causa da sua imagem corporal, para poderem viver em meio à sociedade, que os discrimina constantemente.

\section{Imagem corporal}

\section{Conceito}

Para Schilder (1999), o conceito de imagem corporal se dá a partir da união de dois fatores: a dor e o controle motor dos membros. Esse conhecimento é obtido desde a infância mais remota, quando o bebê sente a dor e a expressa através de sua fisionomia de desconforto ou de choro, até que o adulto descubra a origem desse sofrimento. Com o tempo, a criança toma conhecimento de seu esquema corporal, porque esse é dotado de um fator em constante maturação o ego, com suas intenções e percepções.

\footnotetext{
A imagem corporal é um complexo fenômeno que envolve aspectos cognitivos, afetivos, sociais/culturais emotores. Estáintrinsecamente associada com o conceito de si próprio e é influenciável pelas dinâmicas interações entre o ser e o meio em que vive. $\mathrm{O}$ seu processo de construção/desenvolvimento está associado, nas diversas fases da existência humana, às concepções determinantes da cultura e sociedade. Na história ocorreram modificações das formas de apresentação e representação
} 
dessa imagem, com conseqüências notáveis na relação intra e extra-muros corporais (Adami, Fernandes, Frainer \& Oliveira, 2005, p. 2)

Os autores acima coincidem no que se refere à constante modificação da imagem corporal, por conta de influências de outras imagens, como a visual, tátil, postural e influências socioambientais.

A imagem corporal é constituída daquilo que o indivíduo enxerga no espelho, em que o mesmo estrutura uma figuração mental para si. Esse corpo constituído pelos sentidos da audição, visão, tato, percebe-se de modo singular e pode assimilar sua imagem corporal de maneira positiva ou negativa - tornando-se dependente da aprovação do outro para sentir-se dentro dos "padrões estéticos" (Guimarães, 2007; Mataruna, 2004).

Drudi (2002) aponta que a abordagem psicanalítica concebe a imagem corporal como a unidade da percepção interna e externa em que o indivíduo se desenvolve com o investimento emocional do progenitor, introjetando o sentimento de aconchego ou de rejeição que o influenciará em sua estruturação física e psicológica. Constrói-se a imagem de corpo com base no desejo imaginário de se possuir uma aparência que possa ser aprovada pelo outro.

Para Damasceno, Lima, Vianna, Vianna, Novaes (2005), a imagem corporal é construída de maneira multidimensional, expressando as representações internas do indivíduo sobre sua aparência física a partir da interação com o outro. O julgamento favorável ou desfavorável sobre a imagem corporal é criado por crenças e valores culturais que causam impacto na vida do obeso, levando-se em conta o sexo e a idade, fatores que influenciam o equilíbrio emocional de que o obeso dispõe em meio à obesidade e às complicações que a doença acarreta.

Para Barros (2005), a imagem corporal é originada a partir da junção do aspecto fisiológico, neural e emocional, em que a modificação, o ganho ou perda de um membro alteram a imagem corporal que o indivíduo tem de si.

Além disso, Kaufman (1993) acrescenta que a imagem corporal é o resultado de um grande número de experiências que a pessoa acumula mentalmente durante a vida, reunindo a aparência física, as atitudes e sentimentos, sendo direcionados pelo Sistema Nervoso Central.
Atualmente, a imagem corporal está sendo difundida de forma esteriotipada, e a pessoa que não se enquadra no padrão socialmente imposto sente-se inferiorizada, como é o caso dos indivíduos obesos do sexo feminino, que acabam por refletir exatamente esse cuidado.

\section{Imagem corporal e obesidade}

Schilder (1999) defende que o indivíduo normal preserva a unidade de seu corpo, buscando o equilíbrio na interação das esferas visual, tátil e postural. O movimento dos corpos e o contato entre eles servirá de termômetro para que a pessoa mantenha ou altere sua imagem corporal, porque o indivíduo que não possui equilíbrio emocional, na relação com sua imagem, poderá ter sua personalidade afetada por distúrbios próprios dessa última.

Atualmente, a beleza simboliza sucesso pessoal e profissional. Com isso em vista, os indivíduos perseguem desesperadamente uma "perfeição corporal provisória" e, ao mesmo tempo, acumulam um vazio enquanto seres humanos, porque indiretamente sabem que essa busca por uma imagem corporal ideal, no mundo contemporâneo, não chega a um fim.

A imagem corporal expressa o estado de saúde ou de doença no indivíduo, modificando o modelo postural e o esquema corporal, no que se refere às funções desempenhadas pelo organismo (Schilder, 1999)

Nesse sentido, Andrade (1995), membro da Equipe Multiprofissional do Ambulatório de Obesidade Infantil da Universidade Federal de São Paulo (Unifesp), realizou um acompanhamento psicológico com pais e filhos, no qual o grupo colaborou com o atendimento psicológico, analisando e compreendendo o surgimento e a evolução da obesidade das crianças. Foram identificados quadros psicogênicos e psicodinâmicos desencadeantes de padrões de comportamentos, estados emocionais representados pela rejeição materna e carência afetiva em 26,1\% das crianças obesas, causando depressão e culpa em 17,2\% delas e em seus pais. Esse quadro foi agravado por angústias circunstanciais (por exemplo, a chegada de um novo irmão) em 14,2\% delas, que de certa maneira encontraram recursos internos para se equilibrarem emocionalmente. 
Campos (1995), membro do Ambulatório de Obesidade da Disciplina de Nutrição e Metabolismo do Departamento de Pediatria da Escola Paulista de Medicina (EPM), realizou uma pesquisa com pacientes de 10 a 14 anos de idade, de ambos os sexos, investigando aspectos emocionais envolvidos na diferença das respostas entre os alimentos que a mãe oferece ao filho e os que esse afirma ter recebido. Campos (1995) concluiu que alguns pais desejam que os filhos tornem-se independentes e aprendam a se cuidar sozinhos, e os filhos sentem isso como ameaça e comem para suprir essa carência e manter-se fortes, contra a perda de poder, gerada com o emagrecimento. Por outro lado, há dificuldades na relação mãe e filho, expressadas com amor, ódio e agressões mútuas.

A Organização Mundial da Saúde (OMS, 2008) aponta que a obesidade está sendo vista como um problema de saúde pública e de ordem psicológica, acarretando outras doenças sobre a condição clínica do indivíduo obeso, que incomoda a si e ao outro com um excesso de gordura corporal e uma estética fora do padrão aceito socialmente.

É importante citarmos a pesquisa de Santos, Peres e Benez (2002), que selecionaram um grupo de dez adultos obesos mórbidos, pacientes do ambulatório de um hospital universitário do interior do Estado de São Paulo. Eles não apresentavam problemas psiquiátricos, a maior parte era composta por mulheres, com uma diferença de idade que chegava a 20 anos. Esses pacientes passaram por uma bateria de instrumentos de avaliação física e nutricional, sendo acompanhados por uma equipe de médicos, nutricionista e professor de educação física, em dois momentos distintos, antes e depois de uma intervenção psicológica aprofundada, com o propósito de fornecer base científica para a implementação de um grupo de apoio psicológico. Os estudiosos verificaram que o grupo de obesos mórbidos apresentava uma passividade acentuada numa intervenção que durou semanas, sobre o excesso de gordura corporal do grupo, além do acompanhamento regular no ambulatório. Esses indivíduos foram submetidos ao teste do Desenho da Figura Humana (DFH), que investiga subjetivamente o indivíduo analisando seus conteúdos internos, projetados no desenho de uma figura humana de sexo idêntico ao seu e de outra do sexo oposto, viabilizando uma análise sobre a concepção interna e externa que o indivíduo obeso, principalmente o do sexo feminino, apresentava de "ser no mundo".

Os estudiosos concluíram que os participantes da pesquisa expuseram tendência à imaturidade, passividade, dependência e insegurança. Embora tenham mantido a contenção de impulsos como a agressividade, a dificuldade em aceitar a realidade e as limitações físicas e psicológicas impostas pela obesidade, referentes a uma imagem corporal discriminada socialmente, indicou a necessidade de atendimento psicológico ao grupo.

Grejanin, Pezzo, Nastri, Sanchez, Nascimento e Quevedo (2007) realizaram uma pesquisa com um grupo de profissionais que atuam numa unidade básica de saúde, desenvolvendo o Programa Saúde da Família II (PSF II) no município de São Paulo, com um grupo de pacientes obesos do sexo feminino atendidos nessa unidade. A pesquisa explorou as percepções sobre o "ser obeso" sob a ótica do paciente e dos profissionais da saúde. Constatou-se que, para os profissionais da saúde, o obeso é um indivíduo doente que tem dificuldade em aceitar sua condição. Por outro lado, o grupo de obesas relatou que a dieta recomendada pelos profissionais não está de acordo com as condições financeiras delas, e também que a prática de exercícios físicos não é feita, em sua maioria por falta de motivação, bem-estar físico e mental, sugerindo que os profissionais da saúde devem estabelecer a confiança com o paciente e com seus familiares, para um melhor aproveitamento no tratamento da obesidade.

Para Halpern (1993), a chance de o indivíduo se tornar obeso depende do que ele come, de quanto come e o que gasta de calorias, pois cada organismo possui uma estrutura genética distinta, que reage de maneira diferenciada. Tanto o indivíduo obeso que conhece seus limites quanto aquele que não possui grande conhecimento de sua doença não dispõem de total controle sobre o funcionamento do organismo, que se modifica em cada etapa da vida, fazendo com que deixem de ser culpados, passando a ser inocentes frente à obesidade.

Segundo o Instituto Brasileiro de Geografia e Estatística (IBGE, 2007), entre as mulheres o excesso de peso é diferente no que se refere às regiões (exceto a Nordeste), porque as mulheres, ao contrário dos homens, apresentam um excesso de peso maior nas áreas rurais que nas urbanas. Vale acrescentar que a obesidade afeta 
$8,9 \%$ dos homens adultos e $13,1 \%$ das mulheres adultas do país, e os obesos representam $20 \%$ do total de homens e um terço das mulheres com excesso de peso no Brasil.

Com esse indicativo, Damasceno et al. (2005) realizaram uma pesquisa quantitativa que avaliou a percepção de 186 indivíduos sobre o próprio tipo físico, a silhueta atual (SA), e o desejo referente ao tipo físico ideal, ou silhueta ideal (SI), em que a quantidade de pessoas de cada gênero e suas idades mantiveram-se equilibrados. Utilizaram medidas antropométricas, como índice de massa corpórea (IMC), percentual de gordura $(G \%)$, medidas de estatura e de dobras cutâneas, representando a escala da $\mathrm{SA}$, em conjunto com perguntas e figuras que investigaram as medidas desejáveis para uma SI dos praticantes de caminhada de uma cidade localizada em um dos Estados da região Sudeste do país. Levou-se em consideração que os participantes da pesquisa, como qualquer outro indivíduo, são influenciados pela opinião de familiares e amigos sobre uma imagem corporal padronizada, composta por um corpo magro e esbelto.

Os estudiosos constataram que o instrumento utilizado na pesquisa não foi suficiente para investigar os hábitos alimentares ou distúrbios em meio a essa atividade física e regular dos participantes. Contudo, os indivíduos pesquisados demonstraram noção de seu tipo físico, apresentando um nível de gordura e índice de massa corporal normais, embora necessitados de controle, ao contrário das escolhas feitas sobre a silhueta ideal, que sinalizou o desejo dos homens em adquirir um corpo mais musculoso e com pouca gordura, enquanto as mulheres idealizaram um corpo contendo medidas reduzidas e com pouca gordura, denotando que a maioria os indivíduos pesquisados possuíam um índice de insatisfação com a imagem corporal.

Ferreira e Magalhães (2006) realizaram uma pesquisa com 12 mulheres obesas, pacientes do ambulatório de uma unidade básica de saúde no município do Rio de Janeiro, com idade média de 48 anos, moradoras de áreas de pobreza que circundam regiões nobres do município, pacientes de nutrição que se queixavam constantemente de dores pelo corpo, dificuldades respiratórias e até quadros de infarto, devido ao deslocamento diário de suas residências para o centro urbano do município. Migrantes da região Nordeste do país, exercem o papel de mãe, de gestoras do lar e de profissionais informais, o que exige esforço físico. Esses indivíduos obesos do sexo feminino aceitaram a avaliação do índice de massa corpórea (detectou-se um IMC entre 30 e $35 \mathrm{~m}^{2}$ ) e em seguida participaram de uma entrevista semiestruturada para que os entrevistadores analisassem a concepção do que venha a ser obesidade e para saber se essas mulheres se definiam como obesas. As entrevistadas não correlacionaram a limitação física e a alimentação enriquecida em gordura com a obesidade, pois acreditam que se tornaram obesas por causa da união estável ou da gravidez. Quando questionadas sobre o corpo magro não demonstraram entusiasmo, porque, na concepção delas, não é suficiente para exercer atividades domésticas. Além disso, também acreditam que as formas corporais arredondadas atraem os homens. Por outro lado, gostariam de possuir corpos mais leves, porque têm agilidade no dia a dia.

Se, por um lado, os estudiosos concluíram que a obesidade é para essas mulheres sinônimo de força para o trabalho, por outro elas se queixam da falta de condições financeiras para realizar uma dieta adequada com vistas à perda de massa corporal. Isso resulta na passividade desses indivíduos, que ocultam o incômodo com a própria imagem ao mesmo tempo em que entrevêem nela qualidades.

Pio (2006) realizou um estudo com um grupo de oito mulheres obesas, com faixa-etária entre 25 e 60 anos, em uma unidade básica de saúde situada no interior do Estado de São Paulo, e participantes de um grupo de reeducação alimentar. O objetivo era abordar a questão da obesidade, procurando analisar a percepção de mulheres acerca dos determinantes relacionados ao ganho de peso, permitindo um diagnóstico psicodinâmico e sua relação com a alimentação. Foi aplicado perguntas semidirigidas, com temáticas divididas em quatro categorias: eventos importantes no decorrer da vida, sentimento de solidão, voracidade e privação, imagem corporal e imagem do "eu". Os resultados da pesquisa apontaram que, na tentativa de amenizar sofrimentos e evitar frustrações, a comida seria procurada como um tranquilizante, um prazer infantil perdido (representado pelo desmame), que pode servir como proteção contra os medos e inseguranças internas.

Drudi (2002) fez um estudo comparativo sobre imagem corporal entre mulheres obesas que possuem relacionamento amoroso e outras que não 
têm. No que se refere à imagem corporal, detectouse que o indivíduo obeso que não teve suas qualidades físicas reforçadas ao longo da vida passa a sentir-se inferior diante do outro, pois cada pessoa tem uma estrutura psicológica, influenciável pelo contato com o meio social. O indivíduo obeso é discriminado desde a infância, por ser visto com diferença pelo outro e, principalmente, por permitir que essa diferença ponha-o à margem da sociedade.

Kaufman (1993) complementa que a mulher obesa não tem noção de sua própria identidade feminina, definindo-se em valores masculinos, e engorda com o medo de ser transformada em objeto sexual, passando a ser considerada como a mãe bondosa, neutralizando uma imagem corporal atraente para o outro, pois a obesidade, nesse caso, funciona como proteção. Assim, retira aspectos sexuais e competitivos das interações por ter dificuldades em lidar com isso. Já os indivíduos obesos do sexo masculino são aceitos com mais facilidade, seja por terem boa posição socioeconômica, inteligência ou por outras qualidades.

Nessa perspectiva, Almeida, Santos, Pasian e Loureiro (2005) realizaram um estudo que objetivou investigar a percepção de mulheres quanto ao tamanho e à forma corporal normal, real e ideal, por meio da medida do IMC e da Escala de Desenhos de Silhuetas, utilizada como método de pesquisa. Essas mulheres foram divididas em cinco grupos, de categorias de 1 e 2 = não obesidade; 3 $=$ sobrepeso; 4 e $5=$ obesidade grau I; 6 e $7=$ obesidade grau II; 8 e 9 = obesidade grau III.

Num estudo exploratório com a Escala de Desenhos de Silhuetas, os autores acima investigaram a percepção de tamanho e forma corporal normal, real e ideal, possibilitando a identificação de indicadores de escolhas conflitantes quanto à avaliação do real e do desejável no grupo de mulheres com sobrepeso e obesidade, apontando os prejuízos relacionados à autopercepção corporal.

Tal fato pôde ser ampliado em estudos feitos por Ferreira e Leite (2002) com o objetivo de adaptar e validar o Questionário Multidimensional de Relações Eu-Corpo (que compreende três domínios: aparência ou estética física, competência ou eficácia física e saúde ou integridade física) e a Escala de Estima Corporal, que mede a satisfação com a imagem corporal, em amostras brasileiras, através de dois estudos distintos. O primeiro desses estudos verificou a validade e a consistência da escala, em uma amostra de 277 estudantes universitárias, e o segundo estudo atestou a validade da escala, comparando os resultados obtidos por mulheres obesas e não obesas, ambos fundamentados pela teoria perceptual, que superestima o tamanho do corpo, e também pela teoria subjetiva, caracterizada por influências socioculturais, que faz com que o indivíduo fique insatisfeito com seu corpo, passando a rejeitá-lo. Os resultados obtidos atestaram que as universitárias estão mais satisfeitas com a forma corporal, fato condizente com as mulheres não obesas, ao contrário das mulheres obesas, que possuem insatisfação quanto a suas medidas corporais e à imagem perante o outro. Entretanto, a validade da escala e sua consistência interna são recomendáveis em situações de pesquisas clínicas ou para auxiliar um diagnóstico de avaliação relativo ao nível de satisfação que o indivíduo tem com sua imagem corporal.

Esboçamos acima a importância da imagem corporal para a compreensão de indivíduos obesos, principalmente os do sexo feminino que seguem as imposições do estereótipo social, pois essas determinam seu status e segurança, no que se refere ao grau de atração que exerce no homem. Quando uma mulher sente que não está bonita diante do outro, esse fato pode acarretar perda da autoestima e insegurança, pois o ideal de beleza é dinâmico como o tempo, ou seja, não para, e dessa forma acumulam-se a culpa, a frustração e a ansiedade nesses indivíduos (Penna, 1989).

Segal (2002) defende a Psicoterapia Cognitivo-Comportamental como forma de tratamento, visando à modificação de hábitos de vida do indivíduo obeso, propondo a modificação da ingestão alimentar e o aumento da atividade física, com a medição da motivação do paciente. É necessário que o indivíduo obeso, principalmente o do sexo feminino, relate seus eventos ambientais perante o grupo de iguais, pois dessa forma são identificadas as razões de sua inadaptação. $\mathrm{O}$ paciente obeso sofre com a oferta de alimentação rica em gordura, motivo que pode levá-lo a ter recaídas, apresentando posteriormente padrões alimentares patológicos, como episódios bulímicos ou transtorno de compulsão alimentar periódica. Nesse casos, deve-se encaminhá-lo para uma modalidade terapêutica específica, que trabalhe em longo prazo com a eliminação de pensamentos negativos e autodepreciativos. 
Outro aspecto relevante é a insatisfação com a imagem corporal, que é constante entre pacientes obesos, especialmente entre as mulheres, porque não há consciência de que cada indivíduo possui um conceito de imagem corporal e, acima de tudo, a responsabilidade de desenvolver e fortalecer as qualidades da própria imagem. Devido à insatisfação com a imagem corporal, uma parte dos indivíduos obesos sente tristeza, um estado recorrente que pode isolá-los do convívio coletivo, impedindo-os de tomarem uma atitude diferenciada sobre a própria saúde. Em outros casos, esses indivíduos apresentam um comportamento agressivo, mesmo que as medidas antropométricas presentes no grupo terapêutico sejam semelhantes; isso se dá porque na maioria dos casos o indivíduo inserido num grupo não gosta de obter um desempenho físico ou psicológico inferior ao do outro.

Guimarães (2007) salienta que o excesso de gordura corporal deixa o indivíduo obeso desengonçado ao ponto de sentir-se incomodado, fazendo com que seu amor próprio seja destruído. Em outros casos surge o investimento no aspecto intelectual para compensar a falta de autocontrole sobre a obesidade, que é desgastante.

Para o estudioso é necessário tratar a causa da obesidade, para o controle de seus aspectos físicos e psicológicos. Os últimos podem se configurar como culpa ou outros sentimentos negativos, por conta da falta de atitude em encarar e resolver os problemas de frente. O autor sugere que a partir do momento que o indivíduo obeso se autoavaliar, tendo consciência de sua imagem corporal real e disponibilidade para conquistar o corpo ideal - ou seja, o corpo que ele pode vir a obter com o tratamento da obesidade -, isso fará com que desenvolva uma habilidade emocional para viver bem dentro de sua condição pessoal.

\section{MÉTODO}

No que se refere ao presente estudo, o método foi desenvolvido por meio de pesquisa bibliográfica, constituída da revisão de livros, monografias e artigos online dos últimos oito anos (2001-2008) que abordavam o tema "imagem corporal em indivíduos obesos do sexo feminino".

Partindo do tema, iniciamos um levantamento bibliográfico preliminar sobre a obesidade; fizemos um recorte no sentido de correlacioná-la à imagem corporal em indivíduos do sexo feminino; e a partir de sites especializados em pesquisas científicas voltadas para a psicologia, elaboramos e lançamos descritores pareados, como: obesidade e obesidade, obesidade e obesos, mulheres e obesidade, imagem corporal e obesidade, imagem corporal e obesos, mulher e imagem corporal, imagem corporal e corpo, imagem e corpo, corpo e corporeidade.

Concluída a fase de levantamento bibliográfico, os dados sobre os aspectos psicológicos em indivíduos obesos do sexo feminino foram identificados, analisados e correlacionados qualitativamente, e os aspectos psicológicos de maior incidência foram apresentados em texto discursivo.

\section{ANÁLISE DE RESULTADOS}

O fato de o indivíduo obeso comer de maneira compulsiva tem ligação com suas necessidades emocionais da primeira infância, mais precisamente na fase da ansiedade persecutória, em que o bebê convive com objetos parciais, como o seio bom, que lhe fornece o prazer no contato com o seio e o leite, e o seio mal, que o persegue e tenta aniquilá-lo, fazendo com que o bebê use sua agressividade (inata) para defenderse durante os pequenos ou grandes período de tempo, projetando grande parte de sua libido na luta contra o que lhe ameaçava, introjetando o afeto do seio bom como proteção. A mãe, por sua vez, não compreendendo a angústia da criança, supre as necessidades dessa com alimentação em excesso, fazendo com que o filho passe a buscar ao longo da vida a saciedade de seus instintos com a comida (Klein, 1952, 1982; Kelner, 2004)

Além do alimento (leite), a criança também necessita do afeto, demonstrado através do olhar e da fala da mãe, embora essa não possa estar o tempo todo com a criança, por causa do pai e de outros afazeres. Caso a mãe não promova um investimento narcísico sobre a criança, que necessita de afeto no momento do cuidar/alimentar, a criança poderá apresentar uma depressão infantil, por não ter recebido totalmente o afeto desejado. $\mathrm{O}$ indivíduo que sofreu com o desinteresse afetivo da mãe na fase primitiva da infância será incapaz de construir relações completas, acreditando que o outro (pai) 
roubou o amor e a dedicação da mãe para si, originando-se um vazio interno que será preenchido na primeira oportunidade. No caso do indivíduo obeso, esse vazio poderá ser preenchido pela comida, que terá a função de sufocar ou amenizar situações frustrantes pela vida afora (Winnicott, 1990; Green, 1988; Pio, 2006).

Os pais que se realizam com a concepção e o nascimento de um filho, independente do sexo, tratando-o e encorajando-o com afeto e admiração, realizam um investimento libidinal sobre a criança e contribuem para o fortalecimento da identidade dela. Observando os indivíduos obesos, fica claro que esses não receberam o investimento do afeto que é fornecido primeiramente pela mãe e, em seguida, por outros familiares no decorrer de seu desenvolvimento. Questões relativas à imagem, desempenho escolar, relações de discriminação no grupo, entre outros, permeiam a sensibilidade infantil, fazendo com que o indivíduo obeso sintase em desvantagem por conta de sua gordura corporal, mesmo que tenha caráter e respeito pelo próximo. A infância e a adolescência são fases que possuem grande importância na vida do indivíduo, nas quais o desenvolvimento, a aceitação e a valorização da imagem corporal dependerão em grande parte da aprovação do outro (Andrade, 1995; Campos, 1995; Drudi, 2002; Schilder, 1999).

Nessa perspectiva, a diferença entre os gêneros é traçada desde a infância, porque de um lado os meninos desejam ser fortes e de outro lado as meninas identificam-se extremamente com as modelos de revista e apresentadoras de TV, ambas esculpidas por tratamentos estéticos avançados, comprovando a fidelidade quanto às exigências da mídia. Todo indivíduo que foge ao "padrão de beleza" constituída por uma pele de cor branca, cabelos lisos, olhos claros, corpo magro e esbelto é passível de julgamento, rejeição e críticas, ainda mais se apresentar duas características propícias para sua marginalização, como é o caso mulheres obesas (Couto, 2004; Priore, 2004).

A imagem corporal é um processo de construção e reconstrução na vida do indivíduo, ocasionado pela sua flexibilidade, pela capacidade de adaptação, o que não ocorre com o indivíduo obeso, que permanece numa fase anterior do desenvolvimento, satisfazendo apenas sua oralidade (Kelner, 2004; Schilder, 1999).

A busca por uma imagem corporal perfeita é praticada principalmente por pessoas de um nível econômico favorecido, que investem em seus corpos a fim de deixar claro que pertencem a um grupo seleto, com acesso à sofisticação da tecnologia especializada na estética corporal. Os indivíduos inseridos em classes inferiores economicamente não dedicam os cuidados sonhados para seus corpos, utilizados na maioria dos casos como instrumentos de força para o trabalho, o que faz com que esse grupo desempenhe ajustes sobre uma imagem corporal que é modificada de maneira legítima pelo tempo. Hoje o corpo exerce várias funções sociais. Um indivíduo de um determinado grupo expõe o corpo através da vestimenta, do uso de símbolos e da força relativos ao grupo social a que pertence; um segundo grupo com posicionamento político faz com que o indivíduo envolva-se e participe socialmente de atos partidários, públicos, muitas vezes usando de força para promover ideias $\mathrm{e}$ valores em que ele acredita; um terceiro grupo projeta o excesso do corpo de maneira direta, que é o caso dos indivíduos obesos, que passam uma imagem de força física, que na realidade integra uma doença multifatorial. Por outro lado, há indivíduos que promovem atividades físicas em excesso e o consumo de medicamentos nãorecomendáveis para adquirir massa muscular e uma força física ilusória. Um quarto e último grupo submete o corpo a um frequente e desgastante processo de modificação estética, com a utilização de dietas, procedimentos físicos e cirúrgicos, para que o corpo permaneça no padrão corporal valorizado em sociedade (Schilder, 1999; Ferreira \& Leite, 2002; Carreteiro, 2005).

O homem é dominante em nosso meio, e de acordo com isso fornece atenção e carinho para as mulheres que lhe atraem fisicamente. $\mathrm{O}$ que se observa é que há uma preferência pelas que exibem a imagem corporal ideal, e os indivíduos obesos do sexo feminino são desconsiderados nesse processo. As mulheres dão extrema importância à imagem corporal, acreditando que essa possa lhes proporcionar o sucesso pessoal, e quando não conseguem atingir esses objetivos estéticos, costumam apresentar sentimentos de inferioridade, pois ficam vulneráveis perante o culto ao corpo, passando a cometer excessos não recomendáveis para o bemestar psicológico, seguidos de uma redução das medidas corporais provocadas pela restrição alimentar ou episódios bulímicos, praticados principalmente por indivíduos obesos do sexo 
feminino, que passam ou não por tratamento da obesidade (Penna, 1989; Segal, 2002).

A insatisfação do indivíduo obeso do sexo feminino com o corpo reside na percepção e no desejo de obter outro tamanho e forma corporal que esteja de acordo com as normas socioculturais, que impõem o estereótipo da magreza como atributo positivo, principalmente entre as mulheres, que têm necessidades físicas, de valor social e psíquicas. A mulher obesa prefere isolar-se, buscando no plano de fantasia satisfações que não alcançam na realidade, pois convivem com uma imagem corporal permeada por sentimentos de inferioridade, descontentamento, baixa auto-estima, inibição, ansiedade, angústia, agressividade, tristeza, depressão, distúrbios e distorções referentes ao reconhecimento das medidas corporais, anatômicas, tamanho e forma corporal, apontados nas pesquisas revisadas neste trabalho. Os indivíduos obesos do sexo feminino também convivem com a culpa, por não conseguirem perder peso, ou culpam o outro, pois esse, inconscientemente, carrega frustrações referentes aos objetos parciais da primeira infância.

Portanto, os indivíduos obesos do sexo feminino sofrem por serem alvo de estigma social, emergindo aspectos psicológicos em nível consciente ou inconsciente, na forma de ansiedade, agressividade, passando a subestimar suas medidas corporais, como mecanismos de defesa. Esses indivíduos têm suas habilidades e qualidades comparadas ao corpo obeso, que por sua vez é depreciado pela sociedade, quanto à imagem corporal. (Almeida et al, 2005; Campos, 1995; Damasceno et al, 2005; Ferreira \& Leite, 2002; Kakeshita \& Almeida, 2006; Kaufman, 1993; Penna, 1989; Salve, 2005; Schilder, 1999).

Acredita-se que o atendimento multidisciplinar dedicado ao indivíduo obeso do sexo feminino possa reforçar seus pontos de sucesso pessoal, pois essas pessoas, na maioria dos casos, sufocam-se com a grande ingestão alimentar, sentimentos e emoções provindas do desgaste emocional e físico provocados por uma sociedade submissa ao consumismo e modismo da vida moderna, em que o indivíduo se deixa iludir constantemente por modelos prontos e descartáveis, de valores e atitudes a serem tomadas no cotidiano (Segal, 2002; Santos et al., 2002).

O indivíduo obeso apresenta dificuldades em atingir a maturidade, que é constituída pela fase genital, que propicia a totalidade da identidade.
Dessa forma, ele ameniza sentimentos de baixaestima, medos, impulsos sexuais, ansiedade e agressividade com a comida, porque o indivíduo obeso não encontra compreensão de sua doença em meio ao ambiente, fazendo da gordura uma capa protetora que suprime os impulsos sexuais, as frustrações causadas pelo outro, ou seja, emoções vivenciadas no contato desse indivíduo com o outro (Pio, 2006; Guimarães, 2007).

Atualmente profissionais da Medicina, da Nutrição e da Educação Física avaliam e tratam a obesidade com a promoção de exercícios aeróbicos acompanhados de orientação e acompanhamento nutricional. Já os profissionais da saúde mental, como os psicólogos, atuam sobre a imagem corporal, que é um aspecto de grande importância na vida do indivíduo obeso, principalmente os do sexo feminino, pois é o corpo que estabelece o contato com o outro através do seu dinamismo, relacionando-se de maneira superficial ou profunda, a depender da situação em que esse corpo se coloca para o outro (Ferreira \& Arguelho, 2006; Ferreira \& Magalhães, 2005; Carneiro, 2005; Lottenberg, 2002; Monteiro, Riether \& Burini, 2004).

A partir do exposto, reconhecemos que a obesidade é fácil de ser percebida, porém exige um complexo agrupamento de abordagens científicas para sua compreensão, porque ao mesmo tempo em que a obesidade é tida como uma doença de etiologia multifatorial, que afeta o indivíduo em âmbito psicológico ou físico, percebe-se que ela é usada pelos meios de comunicação como uma opção de vida inadequada, principalmente se comparada à obsessão do homem contemporâneo pelo alcance de uma imagem corporal ideal, ou seja, isenta de gordura.

\section{CONCLUSÃO}

Os objetivos foram alcançados no sentido de termos identificado aspectos psicológicos sobre a imagem corporal em indivíduos obesos do sexo feminino, na forma de ansiedade, que altera o nível da consciência, fazendo com que essas pessoas desejem a diminuição do peso e, ao mesmo tempo, o resgate da "identidade perdida". A tristeza aparece para esses indivíduos como frustração, porque a obesidade foi ganhando espaço na vida deles de maneira gradativa e persistente, processo que se repete no tratamento da doença, seguindo os devidos 
Silva, G. A., Lange, E. S. N.

encaminhamentos médicos e terapêuticos, levandose em conta o desenvolvimento psicodinâmico em cada caso de obesidade. A agressividade das mulheres obesas reside no fato de possuírem características que são vistas com forte discriminação pela sociedade que as cerca, mas também pode estar na falta de atitude em assumir que a própria obesidade é o fator principal de seu insucesso pessoal e social. Em muitos casos, os indivíduos obesos do sexo feminino apresentam um alto índice de insatisfação com a imagem corporal, porque a obesidade é uma doença crônica e que necessita de um monitoramento pessoal e profissional contínuo, mesmo com a utilização de procedimentos cirúrgicos ou aeróbicos avançados, por se tratar de uma doença de causa multifatorial. Entretanto, o fator que mais contribui para a insatisfação com a imagem corporal dos indivíduos obesos do sexo feminino é o olhar de desaprovação ou o distanciamento do outro, praticado muitas vezes de maneira inconsciente.

Tomamos conhecimento de outros aspectos psicológicos, como o vazio, a angústia, a culpa e distúrbios no reconhecimento do tamanho e forma corporal, detectando que não só os aspectos psicológicos, mas também os fatores genéticos, hereditários, endócrinos e principalmente os sócioambientais epsicodinâmicos significativos, contribuem para um mal-estar diversificado e pouco manifesto, mas profundamente latente em muitos dos indivíduos obesos do sexo feminino. Analisamos que os aspectos psicológicos citados acima têm início na primeira infância, quando não houve um investimento de afeto suficiente no vínculo mãe-filho e de outros familiares sobre a criança, no decorrer do desenvolvimento dela, enquanto indivíduo com uma identidade em fase de estruturação. Os aspectos psicológicos de maior incidência correlacionam-se constantemente na vida dos diante do espelho e durante o contato com o outro.

Concluiu-se que mulheres obesas desencadeiam aspectos psicológicos, devido a um vínculo mãe-filho mal resolvido na primeira infância, acrescentando grande importância sobre a etiologia multifatorial da obesidade, na qual se fazem necessárias políticas públicas que possam difundir e reforçar as qualidades do indivíduo obeso do sexo feminino, ampliando a rede de tratamento multidisciplinar para que tenham a oportunidade de receber orientação médica/ nutricional e psicológica necessárias.

\section{REFERÊNCIAS}

Andrade, T. M. (1995). Estudo psicológico de crianças e adolescentes obesos. In M. Fisberg. (Org.). Obesidade na infância e adolescência. Fundo Editorial Byk.

Adami, F., Fernandes, C. T., Frainer, S. E. D., \& Oliveira, R. F. (2005). Aspectos da construção e desenvolvimento da imagem corporal e implicações na educação física. Lecturas: EFy Deportes Revista Digital, 10(83). Recuperado em 11 nov. 2007, em http://www.efdeportes.com

Almeida, N. A. G., Santos, E. J., Pasian, R. S., \& Loureiro, R. S. (2005). Percepção de tamanho e forma corporal de mulheres: Estudo exploratório. Psicologia em Estudo, 10(1), 27-35. Recuperado em 14 nov. 2007, em www.bvs-psi.org.br

Barros, D. D. (2005). Imagem corporal: A descoberta de si mesmo. História, Ciências, Saúde Manguinhos, 12(2), 547-554. Recuperado em 17 nov. 2007, em www.bvs-psi.org.br

Campos, A. L. R. (1995). Aspectos psicológicos da obesidade. In M. Fisberg. (Org.). Obesidade na infância e adolescência. São Paulo: Fundo Editorial Byk.

Carneiro. G. (2005). Patogênese. In M. Claudino. Guia de transtornos alimentares e obesidade: Guia de medicina ambulatorial e hospitalar (p. 203). Barueri: Manole.

Carreteiro, T. C. (2005). Corpo e contemporaneidade. Psicologia em Revista, 11(17), 62-76. Recuperado em 14 mar. 2008, em www.bvs-psi.org.br

Couto, E. S. (2004). Corpos interditados: Notas sobre anatomias depreciadas. In M. L. Strey, \& S. T. Cabedas. Corpos e subjetividades em exercício interdisciplinar (pp. 133-148). Porto Alegre: EDIPUCRS.

Damasceno, O. V., Lima, P. R. J., Vianna, M. J., Vianna, A. R. V., \& Novaes. S. J. (2005, maio-junho). Tipo físico ideal e satisfação com a imagem corporal de praticantes de caminhada. Revista Brasileira Médica Esporte, 11(3), 181-186. Recuperado em 17 nov. 2007, em www.bvs-psi.org.br 
Drudi, V. M. (2002). Corpo e imagem corporal. In V. M. Drudi. A imagem corporal da mulher obesa: $O$ estudo comparativo entre as imagens corporais de mulheres obesas que possuem relacionamento amoroso e das que não o possuem. Trabalho de Conclusão de Curso, Faculdade de Psicologia da Pontifícia Universidade Católica de São Paulo, São Paulo.

Ferreira, J. S, \& Arguelho, R. S. (2006). Percepção dos pacientes frente ao tratamento clínico da obesidade grave. Lecturas: Ef y Deportes Revista Digital, 11(100). Recuperado em 18 jan. 2008, em http://www.efdeportes.com

Ferreira, M. C, \& Leite, N. G. M. (2002). Adaptação e validação de um instrumento de avaliação da satisfação com a imagem corporal. Avaliação Psicológica, 2, 141-149. Recuperado em 17 nov. 2007, em www.bvs-psi.org.br

Ferreira, V. A, \& Magalhães, R. (2005). Obesidade e pobreza: $\mathrm{O}$ aparente paradoxo: Um estudo com mulheres da favela da Rocinha. Caderno: Saúde Pública/Rio de Janeiro, 21(6), 1792-1800. Recuperado em 17 nov. 2007, em www.scielo.org.br

Ferreira, V. A., \& Magalhães, R. (2006). O corpo cúmplice da vida: Considerações a partir dos depoimentos de mulheres obesas de uma favela carioca. Ciência e Saúde Coletiva, 11(2), 483-490. Recuperado em: 18 fev. 2008, em www.bvs-psi.org.br

Green, A. (1988). A mãe morta. In A. Green. Narcisismo de vida, narcisismo de morte (pp. 239-253). São Paulo: Escuta.

Grejanin, D. K. M., Pezzo, H. T., Nastri, V., Sanches, P. P. V., Nascimento, G. D. D., \& Quevedo, P. M. (2007). As percepções sobre o "ser obeso" sob a ótica do paciente e dos profissionais da saúde. Revista Brasileira de Crescimento e Desenvolvimento Humano, 17(3), 37-47. Recuperado em 20 out 2008, em www.bvs-psi.org.br

Guimarães, G. (2007). Obesidade e fatores emocionais. In C. I. Fernandes. Obesidade: E suas múltiplas conseqüências (pp. 133-137). Goiânia: UCG.

Halpern, A. (1993). O obeso: culpado ou inocente. In A. T. Cordás. (Org.). Fome de cão: Quando o medo de ficar gordo vira doença: Anorexia, bulimia, obesidade (pp. 75-82). São Paulo: Maltese.
Instituto Brasileiro de Geografia e Estatística - IBGE. (2007). Com obesidade não se brinca. Recuperado em 13 out. 2007, em http://www.ibge.gov.br/ ibgeteen/datas/saude/obesidade.html

Kaufman, A. (1993). Obesidade feminina e sexualidade. In A T. Cordás (Org.). Fome de cão: Quando o medo de ficar gordo vira doença: Anorexia, bulimia, obesidade obesidade (pp. 83-93). São Paulo: Maltese.

Kakeshita I. S, \& Almeida S. S. (2006). Relação entre índice de massa corporal e a percepção da autoimagem em universitários. Revista Saúde Pública, 40(3), 497-504. Recuperado em 16 nov. 2007, em www.bvs-psi.org.br

Klein, M. (1952/1982). Algumas conclusões teóricas sobre a vida emocional do bebê. In M. Klein et al. Os progressos da psicanálise (pp. 216-229). Rio de Janeiro: Imago.

Kelner, G. (2004). Transtornos alimentares: Um enfoque psicanalítico. Estudos de Psicanálise, (27), 33-44. Recuperado em 16 nov. 2007, em www.bvs-psi.org.br

Lottenberg, A. M. P. (2002). Influência do meio ambiente na gênese da obesidade. In A. Halpern \& C. M. Mancini., Manual de obesidade para o clínico (pp. 45-46). São Paulo: Roca.

Mataruna, L. (2004) . Imagem corporal: Noções e definições. Revista Digital, 10(71), 1-5. Recuperado em 24 fev. 2006, em http: // www.efdeportes.com

Monteiro, R. C. A, Riether, P. T. A., \& Burini, R. C. (2004). Efeito de um programa misto de intervenção nutricional e exercício físico sobre a composição corporal e os hábitos alimentares de mulheres obesas. Revista de Nutrição/Campinas, 17(4), 479-489. Recuperado em 14 nov. 2007, em www.scielo.org

Nunes, M. A., Appolinário, J. C., Galvão, A. L., \& Coutinho, W. (1998). Transtornos alimentares e obesidade. Porto Alegre: Artmed.

Organização Mundial da Saúde - OMS. (2008). Obesidade. Recuperado em 12 abr. 2008, em http: // www.google.com.br"http://pt.Wikipedia.org/wiki/ Organiza $\% C 3 \%$ A $7 \%$ C $3 \%$ A $30 \_$Mundial_da_Sa $\% C 3 \%$ BAde" 
Penna, L. A. (1989). Corporalidade. In L. Penna. Corpo sofrido e mal-amado: As experiências da mulher com o próprio corpo (pp. 21-43). São Paulo: Sumus.

Pio, D. A. M. (2006). Ensaio psicanalítico sobre a percepção de mulheres acerca da sua história de obesidade. Monografia de Conclusão do Curso de Especialização, Faculdade de Medicina de Marília, São Paulo. Recuperado em 8 nov. 2007, em www.bvs-psi.org.br

Priore, M. D. (2004). Corpo a corpo com as mulheres: Transformações do corpo feminino no Brasil. In N. M. L. Strey, Cabedas, S. T. Corpos e subjetividades em exercício interdisciplinar. (pp. 255-266). Porto Alegre: EDIPUCRS.

Salve M. G. C. (2005). Estudo sobre peso corporal e obesidade. Lecturas: Efy Deportes Revista Digital, 10(89). Recuperado em 10 nov. 2007, em http://www.efdeportes.com

Santos, M. A., Peres, R. S., \& Benez, M. S. L. (2002). Contribuições do desenho da figura humana para o delineamento do perfil psicológico de um grupo de obesos mórbidos. Revista de Psicologia, 3(2), 20-29. Recuperado em 16 nov. 2007, em www.bvs-psi.org.br

Segal, A. (2002). Técnicas de modificação de comportamento do paciente obeso: Psicoterapia cognitivo-comportamental. In A. Halpern, C. M. Mancinni. Manual de obesidade para o clínico (pp. 128-131). São Paulo: Roca.

Schilder, P. (1999). A imagem do corpo: As energias construtivas da psique. São Paulo: Martins Fontes.

Winnicott, D. W. (1990). Natureza humana. (Bogomeletz, D. L. Trad.) Rio de Janeiro: Imago.

Recebido: 19/05/2008

Received: 05/19/2008

Aprovado: 16/06/2009

Approved: 06/16/2009

Psicol. Argum. 2010 jan./mar., 28(60), 43-54 